\title{
Определение влияния ацилирования антоцианов яблочной кислотой на удерживание в условиях обращенно-фразовой хроматографии
}

\author{
(C) 2021 Дейнека В.И. ${ }^{1}$, Саласина Я.Ю. ${ }^{1}$, Блинова И.П. ${ }^{1}$, Дейнека Л.А. ${ }^{1}$, \\ Варушкина С.М. ${ }^{1}$, Чулков А.Н. ${ }^{2}$, Селеменев В.Ф. ${ }^{3}$

\begin{abstract}
${ }^{1}$ Белгородский государственный национальный исследовательский университет, Белгород
${ }^{3}$ Воронежский государственный университет, Воронеж
\end{abstract} \\ ${ }^{2}$ Белгородский филиал «Центр оценки качества зерна и продуктов его переработки», Белгород
}

Поступила в редакцию 14.01.2021 г.

DOI: $10.17308 /$ sorpchrom.2021.21/3353

В работе определен видовой состав антоцианов цветков гвоздики традиционной красной и необычных темно-красной и фиолетовой окрасок, а также определен вклад заместителей яблочной кислоты в общее удерживание антоцианов при разделении в условиях обращенно-фазовой ВЭЖХ с использованием диодно-матричного и масс-спектрометрического детектирования. Установлены основные компоненты экстрактов цветков двух сортов гвоздики садовой - алой и темно-красной окраски, как 3-гликозиды пеларгонидина и цианидина (Pg3Glu и Cy3Glu), соответственно, в основном ацилированные яблочной кислотой в положении 6"-Pg3(6"MalylGlu) и Cу3(6"MalylGlu) При этом антоцианы гвоздики садовой третьего сорта (с фиолетовой окраской) были построены на иной основе и состояли в основном из производных цианидин-3,5-диглюкозида (Cy3,5diGlu), также главным образом ацилированных яблочной кислотой, но уже в иной форме, соединяющей оба глюкозидных радикала в цикл. Во всех случаях электронные спектры поглощения соединений лишь незначительно (на 0.5-1 нм) батохромно сдвигаются при ацилировании. Антоцианы сухих цветков сорта «Мираж» гвоздики турецкой состояли из производных Cy3Glu и Cy3,5diGlu, также ацилированных яблочной кислотой. Последовательность элюирования всех соединений не зависит от составов подвижных фаз системы «ацетонитрил-муравьиная кислота-вода», приемлемых для ВЭЖХ-анализа. Отмечено, что фактор удерживания, $k(i)$, антоцианов увеличивается в 2.5-3.5 раза в зависимости от состава подвижной фазы при ацилировании яблочной кислотой в положение 6" Cy3Glu и Pg3Glu и только на 25-40\% для Cy3,5diGlu, что позволяет анализировать состав антоцианов в изократическом режиме элюирования. Впервые сравниваются два варианта карт разделения как $\log k(i) v s$ (объемная доля $\mathrm{CH}_{3} \mathrm{CN}$ ) с использованием квадратичной зависимости и как $\log k(\mathrm{i}) v s \log k(\mathrm{Cy} 3 \mathrm{Glu})$. Показано, что экстраполяция удерживания на подвижные фазы с нулевым содержанием воды приводит к сходным результатам в обоих случаях.

Ключевые слова: антоцианы, ацилированные яблочной кислотой, цветки гвоздики, ВЭЖХ, вклад ацильных групп в удерживание, карты разделения.

\section{Введение}

Природные антоцианы, синтезируемые в различных частях растений, являются гликозидами антоцианидинов (агликонов). Гликозилирование положения 3 агликона (схема 1) существенно стабилизирует антоцианы (по сравнению с агликонами) [1], и поэтому агликоны (антоцианидины) практически не встречаются в природе. Антоцианы могут содержать гликозидные заместители дополнительно в одном или в нескольких других положениях агликона [2]. Наконец, углеводные заместители антоцианов могут быть ацилированными органическими кислотами. К настоящему времени в природных источниках найдены антоцианы, ацилированные алифатическими 
кислотами: уксусной, малоновой, яблочной, янтарной, щавелевой и винной, и ароматическими кислотами: производными коричной и бензойной кислот.

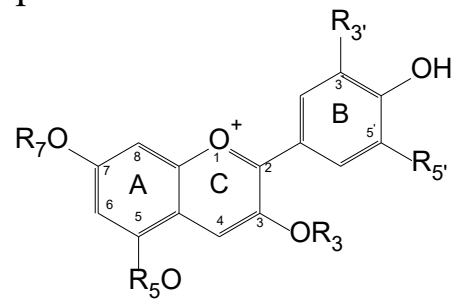

Строение антоцианов во флавилиевой форме The structure of anthocyanins in flavylium form

Хроматографическое поведение антоцианов представляет особый интерес с точки зрения теории хроматографии. Антоцианы, как органические соединения, обладающие высокой гидрофильностью и связанной с ней высокой растворимостью в воде [3], к тому же имеющие положительный заряд на органической основе, должны обладать низким сродством к привитой обращенной фазе. Однако они прекрасно удерживаются в условиях обращенно-фазовой хроматографии в подвижных фазах с умеренным содержанием органических модификаторов при их содержании, не допускающем коллапс фаз, как это происходит при ВЭЖХ других водорастворимых природных красителей - бетацианинов [4]. При этом плоская структура антоцианидиновой основы позволяет ей внедряться в привитую фазу, несмотря на наличие заряда. Из этого можно сделать вывод о том, что заряд компенсируется образованием ионной пары с анионом из подкисленной подвижной фазы. Вероятно, именно поэтому удерживание антоцианов возрастает при добавлении к элюентам, подкисленным трифторуксусной кислотой, солей этой (или хлорной) кислоты [5]. Внедрение именно флавилиевой части молекулы в подвижную фазу подтверждается также независимостью (или слабой зависимостью) удерживания однотипных гликозидов от положения ОНили $\mathrm{CH}_{3} \mathrm{O}$-групп в кольцах В или $\mathrm{A}$, что характерно для распределительного механизма удерживания веществ в ОФ
ВЭЖХ [6]. Гликозидная (углеводная) часть антоцианов не способна проникать в привитую фазу, оставаясь на ее поверхности. В таком случае ориентация гидроксильных групп углеводных заместителей существенно влияет на прочность связи с привитой фазой, поэтому изомеры по этой части - галактозиды или глюкозиды, арабинозиды или ксилозиды, - разделяются при любых составах подвижных фаз. В таком случае ацилирование гликозидных радикалов может привести к изменению удерживания, чувствительного к положению ацилирования [7].

Данная работа посвящена исследованию зависимости удерживания антоцианов при ацилировании яблочной кислотой на примере антоцианов цветков гвоздик.

\section{Экспериментальная часть}

Цветки гвоздики садовой (Dianthus caryophyllus L.) трех типов окраски (сорта неизвестны) были приобретены в магазине для цветов, а гвоздика турецкая (Dianthus barbatus L.) сорта «Мираж» была выращена из семян фирмы Русский огород.

Лепестки цветков экстрагировали растиранием в фарфоровой ступке под слоем экстрагента - 0.1 М водного раствора соляной кислоты. Порции экстракта отделяли от остатка фильтрованием через бумажный фильтр. Полученный экстракт очищали методом твердофазной экстракции на патронах ДИАПАК С18 [7]. Хроматограммы записывали сразу после реэкстракции антоцианов и хранили в холодильнике $\left(4^{\circ} \mathrm{C}\right)$ в течение не более 2 -х дней. Установлено, что при хранении при комнатной температуре происходит деацилирование антоцианов с образованием соответствующих неацилированных продуктов, искажающее начальный состав экстракта. Для хранения лепестки цветков высушивали при комнатной температуре вне доступа прямого солнечного света. 
Разделение осуществляли на оборудовании Agilent 1200 Infinity с диодно-матричным и масс-спектрометрическим детекторами. В работе использовали хроматографические колонки: $150 \times 4.6$ мм Symmetry C18 (3.5 мкм) - для серийных исследований и 150×2.1 мм Kromasil 1005С18 - при масс-спектрометрическом детектировании. Для элюирования использовали элюенты, содержащие 10 об.\% $\mathrm{HCOOH} \mathrm{и} \mathrm{6-20} \mathrm{об. \%} \mathrm{CH}_{3} \mathrm{CN}$ в воде. Во всех случаях скорость подачи подвижной фазы была постоянной $0.8 \mathrm{~cm}^{3} /$ мин. Мертвое время определяли по удерживанию щавелевой кислоты.

Хроматограммы регистрировали и обрабатывали программой Agilent ChemStation. Результаты идентификации антоцианов представлены в табл. 1 .

\section{Обсуждение результатов}

Антоциианы ияветков гвоздики. Антоцианы цветков некоторых видов гвоздики (Dianthus) как и некоторые другие цветки семейства гвоздичные (Caryophyllaceae) уникальны тем, что в них по литературным данным синтезируются антоцианы, ацилирован-ные яблочной кислотой [8]. Строение таких антоцианов было определено в серии опубликованных ранее работ [9-11]. Поэтому в настоящей работе только подтверждали известное строение, анализируя электронные спектры поглощения и массспектры хроматографически разделенных компонентов экстрактов.
Хроматограммы экстрактов цветков гвоздики садовой, Dianthus caryophyllus L., трех окрасок и одного экстракта гвоздики турецкой Dianthus barbatus L., представлены на рис. 1. При этом основные компоненты первых трех экстрактов имели характеристические различающиеся электронные спектры поглощения, рис. 2.

Так основной антоциан экстракта цветков темно-красного цвета образован производным цианидина, в котором заместители имеются только в положении 3 , а судя по масс-спектру это - цианидин-3(6"малонилглюкозид), Cy3(6"MalilGlu). Кроме этого соединения на хроматограмме обнаруживается маленький пик неацилированного Cy3Glu, что свидетельствует о том, что использованная в работе пробоподготовка корректна и не приводит потере лабильной [8] ацильной группы.

Красно-фиолетовая окраска гвоздики садовой оказалась образованной в основном цианидин-3,5-диглюкозидом, в котором ацилирующая яблочная кислота объединила оба глюкозидных остатка в макроцикл, 3,5-ди-О-( $\beta$-глюкопирано-зил) цианидин $\quad 6 "$-O-4,6"'-O-l-цикли-ческий малат, CуCycloMalil3,5diGlu (81.1 мол.\%). $\mathrm{Pg} 3 \mathrm{G}$, и основной компонент - пеларгонидин-3-(6"-малилглюкозид), 93.1 моль.\% $\operatorname{Pg} 3(6 \mathrm{MG})$.

Алая окраска гвоздики садовой обусловлена биосинтезом производных пеларгонидина: минорный компонент пеларгонидин-3-глюкозид (1), 5.0 мол. \%

Таблица 1. Параметры антоцианов цветков гвоздик различной окраски Table 1. Parameters of anthocyanins of carnation flowers of various colours

\begin{tabular}{|c|c|c|c|c|c|}
\hline No & $\begin{array}{c}\text { Начальный } \\
\text { антоциан }\end{array}$ & $\begin{array}{c}\text { Позиция ацилирова- } \\
\text { ния }\end{array}$ & $\log k(i)^{*}$ & $\mathrm{~m} / \mathrm{z}$ & $\lambda_{\max }, \mathrm{nm}$ \\
\hline 1 & \multirow{2}{*}{ Cy3Glu } & неацилированный & 0.199 & $449.2(287.1)$ & 517 \\
\hline 2 & & $6^{\prime \prime}$ & 0.645 & $565.2(287.1)$ & 517 \\
\hline 3 & \multirow{2}{*}{ Pg3Glu } & неацилированный & 0.448 & $433.1(271.1)$ & 502 \\
\hline 4 & & $6^{\prime \prime}$ & 0.895 & $549.2(271.1)$ & 502 \\
\hline 5 & \multirow{3}{*}{ Cy3,5diGlu } & неацилированный & -0.210 & $611.2(287.1)$ & 515 \\
\hline 6 & & $6^{\prime \prime}$ & -0.110 & $727.2(287.1)$ & 516.5 \\
\hline 7 & & 6"+6"'(циклический) & 0.598 & $709.2(287.1)$ & 518 \\
\hline
\end{tabular}

*в элюенте состава 8.8 об.\% $\mathrm{CH}_{3} \mathrm{CN}, 10$ об.\% НСООН в воде/* in the eluent of the composition 8.8 vol. $\% \mathrm{CH}_{3} \mathrm{CN}, 10$ vol. $\% \mathrm{HCOOH}$ in water 


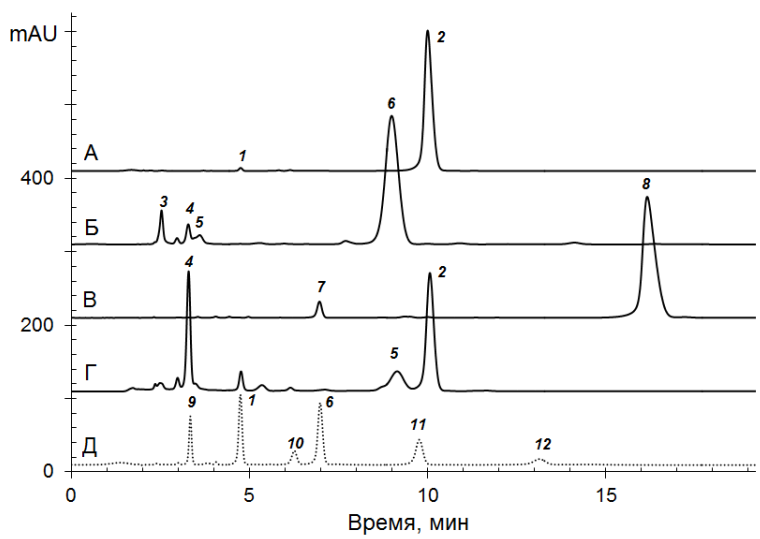

Рис. 1. Хроматограммы экстрактов цветков некоторых гвоздик

Колонка: $150 \times 4.6$ мм Symmetry C18, 3.5 мкм, $40^{\circ} \mathrm{C}$, подвижная фаза: 8.8 об.\% $\mathrm{CH}_{3} \mathrm{CN}, 10$ об.\% $\mathrm{HCOOH} \mathrm{в} \mathrm{воде,} 0.8 \mathrm{~cm}^{3} /$ мин, детектирование 515 нм. Экстракты: A - Dianthus caryophyllus темнокрасного цвета; Б - Dianthus caryophyllus красно-фиолетового цвета; В - Dianthus caryophyllus алого цвета; Г - Dianthus barbatus сорта Мираж; Д - смесь 3-глюкозидов шести основных антоцианидинов. Антоцианы: 1 - Cy3Glu; 2 - Су3 (6"MalilGlu); 3 - Cy3,5triGlu; 4 - Су3,5diGlu;

5 - Cy3(6"MalilGlu)5Glu; 6 - Cy3,5(cycloMalildiGlu); 7 - Pg3Glu; 8 - Pg3(6"MalilGlu); 9 - Dp3Glu; 0 - Pt3Glu; 11 - Pn3Glu; 12 - Mv3Glu

Fig. 1. Chromatograms of extracts of flowers of some carnations

Column: 150 x $4.6 \mathrm{~mm}$ Symmetry C18, $3.5 \mu \mathrm{m}, 40^{\circ} \mathrm{C}$, mobile phase: 8.8 vol. $\% \mathrm{CH}_{3} \mathrm{CN}, 10$ vol. $\%$ $\mathrm{HCOOH}$ in water, $0.8 \mathrm{ml} / \mathrm{min}$, detection at $515 \mathrm{~nm}$. Extracts: A - Dianthus caryophyllus dark red;

Б - Dianthus caryophyllus red-purple colour; B - Dianthus caryophyllus scarlet; $\Gamma$ - Dianthus barbatus

Mirage variety; Д - a mixture of 3-glucosides of six main anthocyanidins. Anthocyanins: 1 - Cy3Glu;

2 - Cy3 (6"MalilGlu); 3 - Cy3.5triGlu; 4 - Cy3.5diGlu; 5 - Cy3 (6"MalilGlu) 5Glu; 6 - Cy3.5 (cycloMa-

lildiGlu); 7 - Pg3Glu; 8 - Pg3 (6"MalilGlu); 9 - Dp3Glu; 10 - Pt3Glu; 11 - Pn3Glu; 12 - Mv3Glu

Таким образом, недавно появившиеся в продаже цветки гвоздики садовой необычных темно-красной и красно-фиолетовой окрасок синтезируют в лепестках цветков производные цианидина, хотя по литературным данным подобные варианты окраски могут быть обусловлены и биосинтезом производных только пеларгонидина или только цианидина [12]. Это важно, поскольку обычно смещение окраски в синюю область характерно для замены производных цианидина на производные дельфинидина, которые были обнаружены лишь в некоторых трансгенных сортах гвоздики [13]. При этом, скорее всего, не характерная для производных цианидина красно-фиолетовая окраска обусловлена образованием сложных супрамолекулярных структур, по

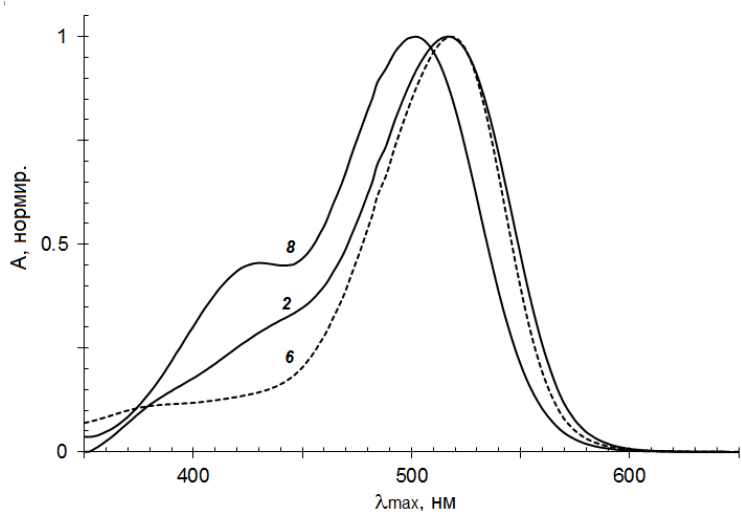

Рис. 2. Электронные спектры поглощения основных компонентов экстрактов цветков гвоздики садовой различных цветов. Нумерация антоцианов как на рис. 1

Fig. 2. Electronic absorption spectra of the main components of extracts of clove carnation flowers of various colours. Numbering of anthocyanins as in Fig. 1 
Таблица 2. Параметры уравнения (2) для удерживания производных цианидина

Table 2. Parameters of equation (2) for the retention of cyanidine derivatives

\begin{tabular}{|l|l|c|c|c|c|}
\hline \multirow{2}{*}{ №* } & \multirow{2}{*}{ Строение антоциана } & \multicolumn{4}{|c|}{ Параметры уравнения (2) } \\
\cline { 3 - 6 } & & $a_{0}$ & $a_{1}$ & $a_{2}$ & $\mathrm{R}^{2}$ \\
\hline 1 & Су3Glu & 1.792 & -0.226 & $4.74 \cdot 10^{-3}$ & 0.99999 \\
\hline 2 & Cy3(6"MalilGlu) & 2.607 & -0.287 & $6.19 \cdot 10^{-3}$ & 1.00000 \\
\hline 4 & Cy3,5diGlu & 1.591 & -0.251 & $4.87 \cdot 10^{-3}$ & 1.00000 \\
\hline 5 & Cy3(6"MalilGlu)5Glu & 1.814 & -0.264 & $4.75 \cdot 10^{-3}$ & 1.00000 \\
\hline 6 & СуCycloMalil3,5diGlu & 2.648 & -0.289 & $6.43 \cdot 10^{-3}$ & 1.00000 \\
\hline
\end{tabular}

типу обнаруженных, например, в лепестках голубых васильков, Centaurea cyanus [14].

Набор антоцианов цветков гвоздики турецкой сорта «Мираж» включал набор найденных ранее антоцианов, но в ином соотношении, хотя следует учесть, что хроматограмма была записана для образца, хранившегося один год в засушенном виде.

Хроматографическое поведение антоичанов изветков гвоздики. Для исследования хроматографического поведения антоцианов цветков гвоздики рассмотрим карту разделения, построенную в традиционных координатах: логарифм фактора удерживания, $\operatorname{lgk}(\mathrm{i})$, как функция объемной доли ацетонитрила $\phi\left(\mathrm{CH}_{3} \mathrm{CN}\right)$, рис. 3.

Отклонение от прямолинейной зависимости по уравнению Снайдера ([15], уравнение 1) в использованных координатах очевидно, но все экспериментальные данные прекрасно аппроксимируются квадратичной зависимостью ([15], уравнение 2 ).

$$
\lg k(i)=a_{0}-a_{1} \cdot \phi\left(\mathrm{CH}_{3} \mathrm{CN}\right)
$$

$\lg k(i)=a_{0}-a_{1} \cdot \phi\left(\mathrm{CH}_{3} \mathrm{CN}\right)+a_{2} \cdot \phi^{2}\left(\mathrm{CH}_{3} \mathrm{CN}\right)(2)$

Параметры уравнения (2) для производных цианидина представлены в табл. 2. Высокие значения $\mathrm{R}^{2}$ свидетельствуют о хорошей применимости квадратичного уравнения, поэтому можно использовать полученные данные для прогнозирования удерживания за пределами составов подвижных фаз, использованных при построении карты разделения. Очевидно, что при полном отсутствии ацетонитрила в подвижной фазе произойдут две инверсии времен удерживания соседних пиков на хроматограмме: Cy3Glu и Cy3(6"MalilGlu)5Glu, а также пары СуСуcloMalil3,5diGlu и Сy3(6"MalilGlu), но удерживания всех веществ будут очень большими, а при приемлемых для разделения составах подвижной фазы все компоненты смеси хорошо разделяются.

Другой вариант построения карты разделения - по методу относительного анализа удерживания [16] проще, поскольку позволяет вследствие линейности уравнений (3) использовать набор данных даже только для двух составов подвижных фаз.

$$
\lg k(i)=a_{0}+a_{1} \cdot \lg k(C y 3 G l u)
$$

Результаты, полученные для того же базиса, что и в изложенном выше способе, представлены на рис. 3 и табл. 3. Это позволяет впервые сопоставить два различных подхода для сопоставления удерживания, сравнив результаты аппроксимации удерживания на нулевое содержание ацетонитрила, $a_{0}$ для Cy3Glu по уравнению (2). Подставив это значение в уравнения относительного удерживания для остальных веществ, можно получить параметры удерживания остальных производных и сопоставить их с данными, полученными по уравнению (2). Различие этих параметров приведено в табл. 3 в скобках в крайне правом столбце. Как следует из представленных данных, максимальное расхождение между двумя рядами данных составляет только $5 \%$, что говорит о хорошей согласованности обоих методов, несмотря на аппроксимацию далеко за пределы использованных составов подвижных фаз. 
Таблица 3. Параметры уравнения (3) для удерживания производных цианидина относительно удерживания Cy3Glu

Table 3. Parameters of equation (3) for the retention of cyanidine derivatives relative to the retention of Cy3Glu

\begin{tabular}{|l|l|c|c|c|c|}
\hline \multirow{2}{*}{ №* } & \multirow{2}{*}{ Строение антоциана } & \multicolumn{2}{|c|}{$\begin{array}{c}\text { Параметры } \\
\text { уравнения (3) }\end{array}$} & \multicolumn{2}{|c|}{ Удерживание при отсутствии $\mathrm{CH}_{3} \mathrm{CN}$} \\
\cline { 3 - 6 } & & $a_{0}$ & $a_{1}$ & По уравнению (3) & По уравнению (2) \\
\hline 1 & Cу3Glu & 0 & 1 & 1.792 & 1.792 \\
\hline 2 & Су3(6"MalilGlu) & 0.402 & 1.227 & 2.601 & $2.607(-0.2 \%)$ \\
\hline 4 & Cy3,5diGlu & -0.431 & 1.154 & 1.637 & $1.591(+2.8 \%)$ \\
\hline 5 & Cy3(6"MalilGlu)5Glu & -0.350 & 1.261 & 1.910 & $1.814(+5.0 \%)$ \\
\hline 6 & CyCycloMalil3,5diGlu & 0.350 & 1.248 & 2.586 & $2.648(-2.4 \%)$ \\
\hline
\end{tabular}

Наклон линий на рис. 3 и рис. 4 пропорционален числу молекул ацетонитрила, высвобождаемых при сорбции каждого из антоцианов. При этом анализ изменения хроматографического поведения антоцианов удобнее проводить по линейным уравнениям (3). Так, добавление малильного радикала в случае Cy3Glu cyщественно сильнее сказывается на удерживании по сравнению с аналогичным изменением структуры при ацилировании Cy3,5diGlu и сильнее зависит от состава подвижной фазы. При этом для всех составов подвижных фаз разность между факторами удерживания при добавлении малильного радикала в положение 6" для Cy3Glu и Pg3Glu практически одинакова

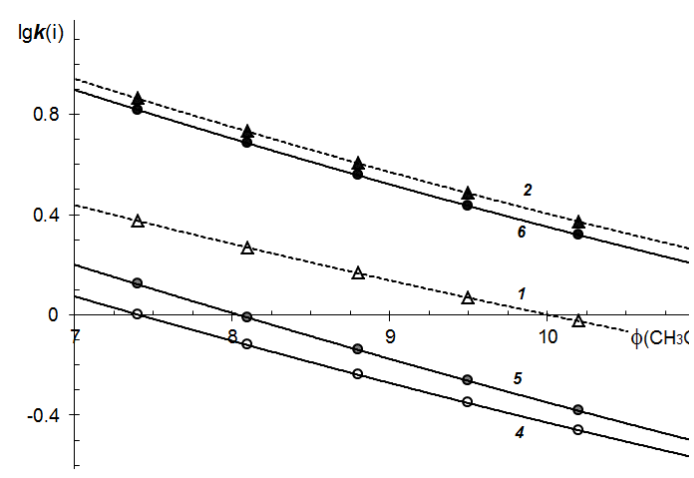

Рис. 3. Зависимость удерживания антоцианов от содержания (объемной доли) ацетонитрила в подвижной фазе.

Нумерация антоцианов как на рис. 1

Fig. 3. Dependence of the retention of anthocyanins on the content (volume fraction) of acetonitrile in the mobile phase. The anthocyanins are numbered as in Fig. 1
- расхождение не превышает 1.5\%. Поэтому, скорее всего, и при ацилировании яблочной кислотой дельфинидин-3-глюкозида в трансгенных цветках гвоздики можно предполагать такое же изменение параметров удерживания. Величина вклада ацильной группы может быть определена по уравнениям (3) с параметрами, указанными в табл. 3.

Однако, аналогичный параметр для введения малильного радикала в то же положение Cy3,5diGlu почти в три раза меньше, что указывает, по всей вероятности, на иное расположение антоциана на поверхности обращенной фазы. Отметим, что подобное изменение вкладов функциональных групп в удерживания при замене стартовых 3-глюкозидов на

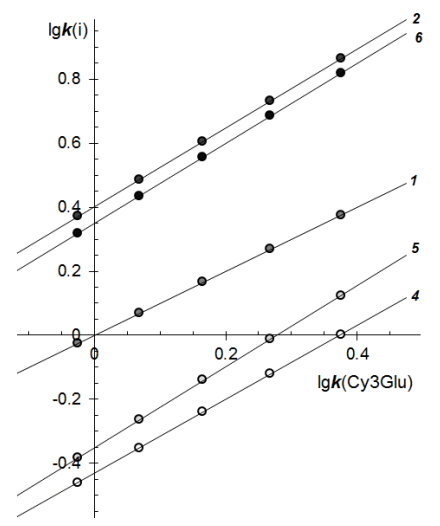

Рис. 4. Относительеон удерживание антоцианов в элюентной системе « $\mathrm{CH}_{3} \mathrm{CN}$ и 10 об. \% НСООН в воде». Нумерация антоцианов как на рис. 1

Fig. 4. Relative to the retention of anthocyanins in the eluent system " $\mathrm{CH}_{3} \mathrm{CN}$ and 10 vol.\% HCOOH in water". The anthocyanins are numbered as in Fig. 1 
3,5-диглюкозиды было получено в нашей лаборатории и для иных вариантов ацилирования (т.е. для ацилирования уксусной [17] или малоновой [18] кислотами).

\section{Заключение}

Удерживание антоцианов увеличивается при их ацилировании яблочной кислотой, но это увеличение относительно не велико и позволяет записывать хроматограммы неацилированных и ацилированных антоцианов в изократическом режиме. Показано, что карты разделения, построенные по двум альтернативным способам, принципиально согласовыва-

\section{Список литературы}

1. Dao L.T., Takeoka G.R., Edwards R.H. et al. // J. Agric. Food Chem. 1998. Vol. 46. pp. 35643569 .

2. Welch C.R., Wu Q., Simon J.E. // Curr Anal Chem. 2008. Vol. 4. pp. 75-101.

3. Дейнека В.И., Дейнека Л.А., Сидоров А.Н. и др. // Журн. физ. химии. 2016. Т. 90. № 4. С. 622-624.

4. Саенко И.И., Дейнека В.И., Дейнека Л.А. // Журн. аналит. химии. 2015. Т. 70. № 7. С. 777-781.

5. Григорьев А.М., Дейнека В.И., Рудаков О.Б. // Сорбционные и хроматографические проиессы. 2005. Т. 5. № 4. С. 518-534.

6. Дейнека В. И., Дейнека Л.А., Саенко И.И. и др. // Журн. физ. химии. 2015. Т. 89. № 7. C. $1172-1177$.

7. Дейнека В.И., Сидоров А.Н., Дейнека Л.А. // Журн. аналит. химии. 2016. Т. 71. № 11. C. 1203-1208.

8. Harborne J.B., Boardley M. // Z. Naturforsch. 1985. Vol. 40c. pp. 305-308. ются между собой, показывая близкие результаты для аппроксимации параметров удерживания далеко за пределы использованных составов подвижных фаз (на нулевое содержание ацетонитрила). Установлено, что зависимость вкладов ацильной группы в удерживание зависит от строения основ и от состава подвижной фазы. Приведены параметры уравнений относительного удерживания, позволяющие рассчитать удерживание ацилированных производных по удерживанию неацилированных соединений.

9. Terahara N., Yamaouchi M.-A., Takeda K. et al. // Phytochem. 1986. Vol. 25. No 7. pp. 1715-1717.

10. Bloor S.J. // Phytochem. 1998. Vol. 49. No 1. pp. 225-228.

11. Nakayama M., Koshioka M., Yoshida H. et al. // Phytochem. 2000. Vol. 55. pp. 937-939.

12. Okamura M., Nakayama M., Umemoto N. et al. // Euphytica. 2013. Vol. 191. pp. 45-56.

13. Fukui Y., Tanaka Y., Kusumia T. et al. // Phytochem. 2003. Vol. 63. pp. 15-23

14. Takeda K., Tominaga S. // Bot. Mag. Tokyo. 1983. Vol. 96. pp. 359-363.

15. Schoenmakers P.J., Billiet H.A.H., Tussen R. et al. // J. Chromatogr. 1978. Vol. 149. pp. 519-537.

16. Дейнека В.И. // Журн. физ. химии. 2006. Т. 80. № 3. С. 511-516.

17. Дейнека В.И., Кульченко Я.Ю., Дейнека Л.А. и др. // Сорбиионные и хроматографические проиессы. 2016. Т. 16. №. 4. С.464-471.

18. Кульченко Я.Ю., Дейнека В.И., Чулков А.Н. и др.// Сорбиионные и хроматографические прочессы. 2018. Т. 18. № 4. С. 588-597. 


\title{
Determination of the effect of acylation of anthocyanins with malic acid on retention under conditions of reversed phase chromatography
}

\author{
(C) 2021 Deineka V.I. ${ }^{1}$, Salasina Ya. Yu. ${ }^{1}$, Blinova I.P. ${ }^{1}$, Deineka L.A. ${ }^{1}$, \\ Varushkina S.M. ${ }^{1}$, Chulkov A.N. ${ }^{2}$, Selemenev V.F. ${ }^{3}$ \\ ${ }^{1}$ Belgorod State National Research University, Belgorod, Russian Federation \\ ${ }^{2}$ Belgorod branch "Center for assessing the quality of grain and products of its processing", \\ Belgorod, Russian Federation \\ ${ }^{3}$ Voronezh State University, Voronezh, Russian Federation
}

\begin{abstract}
In this study, the species composition of anthocyanins of carnation flowers of traditional red and unusual dark red and violet colours was determined, and the contribution of malic acid substituents to the total retention of anthocyanins during separation under conditions of reversed-phase HPLC using diode-matrix and mass spectrometric detection was determined. The main components of the extracts of flowers of two varieties of clove carnation, with a scarlet and dark red colour, 3-glycosides of pelargonidin and cyanidin (Pg3Glu and Cy3Glu), respectively, mainly acylated with malic acid in position 6"-Pg3 (6"MalylGlu) and Cy3 (6"MalylGlu) were established. In this case, the anthocyanins of the clove carnation of the third variety (with a purple colour) had different basis and consisted mainly of cyanidin-3,5-diglucoside derivatives (Cy3,5diGlu), also mainly acylated with malic acid, but already in a different form, connecting both glucoside radicals in a cycle. In all cases, the electronic absorption spectra of the compounds were only slightly (by $0.5-1 \mathrm{~nm}$ ) bathochromically shifted upon acylation. Anthocyanins of dry flowers of the variety "Mirage" of sweet William consisted of derivatives of Cy3Glu and Cy3,5diGlu, also acylated with malic acid. The elution sequence of all compounds did not depend on the compositions of the mobile phases of the "acetonitrile - formic acid - water" system, which are acceptable for HPLC analysis. It is noted that the retention factor, $k(i)$, of anthocyanins increased by 2.5-3.5 times depending on the composition of the mobile phase upon acylation with malic acid at the 6 position of Cy3Glu and Pg $3 \mathrm{Glu}$, and only by $25-40 \%$ for Cy3.5diGlu, allowing to analyse the composition of anthocyanins in the isocratic elution mode. For the first time, two variants of separation maps were compared as $\log k(i)$ $v s \phi$ (volume fraction of $\mathrm{CH}_{3} \mathrm{CN}$ ) using a quadratic dependence and as $\log k(\mathrm{i}) v s \log k(\mathrm{Cy} 3 \mathrm{Glu}$ ). It was shown that the extrapolation of retention to mobile phases with zero water content leads to similar results in both cases.
\end{abstract}

Keywords: anthocyanins acylated with malic acid, carnation flowers, HPLC, contribution of acyl groups to retention, separation maps.

\section{References}

1 Dao L.T., Takeoka G.R., Edwards R.H. et al. J. Agric. Food Chem. 1998, Vol. 46, pp. 35643569. https://doi.org/10.1021/jf980359v

2. Welch C.R., Wu Q., Simon J.E. Curr. Anal. Chem. 2008, Vol. 4, pp. 75-101. doi:10.2174/ 157341108784587795

3. Deineka V.I., Sidorov A.N., Deineka L.A. et al., Russ. J. Phys. Chem. A, 2016, Vol. 90, No 4, pp. 861-863. https://doi.org/10.1134/ S0036024416040075

4. Saenko I.I., Deineka V.I., Deineka L.A., $J$. Anal. Chem., 2015, Vol. 70, No 7, pp. 892-896. https://doi.org/10.1134/S1061934815070138

5. Grigoriev A.M., Deineka V.I., Rudakov O.B., Sorbtsionnye $i$ khromatograficheskie protsessy, 2005, Vol. 5, No 4, pp. 518-534

6. Deineka V.I., Deineka L.A., Saenko I.I. et al., Russ. J. Phys. Chem. A, 2015, Vol. 89, No 7, pp. 1300-1304. https://doi.org/10.1134/ 0036024415070079

7. Deineka V.I., Sidorov A.N., Deineka L.A., J. Anal. Chem., 2016, Vol. 71, No 11, pp. 1145$1150 . \quad$ https://doi.org/10.1134/S10619348 16110034

8. Harborne J.B., Boardley M., Z. Naturforsch. 1985, Vol. 40c, pp. 305-308. https://doi.org/ 10.1515/znc-1985-5-603

9. Terahara N., Yamaouchi M.-A., Takeda K. et al. Phytochem. 1986, Vol. 25, No 7, pp. 17151717. https://doi.org/10.1016/S0031-9422(00) 81242-X

10. Bloor S.J. Phytochem. 1998, Vol. 49, No 1, pp. 225-228. https://doi.org/10.1016/S00319422(97)01051-0

11. Nakayama M., Koshioka M., Yoshida H. et al., Phytochem., 2000, Vol. 55, pp. 937-939. https://doi.org/10.1016/S0031-9422(00)00263-6 
12. Okamura M., Nakayama M., Umemoto N. et al. Euphytica. 2013, Vol. 191, pp. 45-56 DOI 10.1007/s10681-012-0859-x

13. Fukui Y., Tanaka Y., Kusumia T. et al. Phytochem. 2003, Vol. 63, pp. 15-23. DOI: $10.1016 / \mathrm{s} 0031-9422(02) 00684-2$

14. Takeda K., Tominaga S. Bot. Mag. Tokyo. 1983, Vol. 96, pp. 359-363. https://doi.org/10.1007/BF02488180
15. Schoenmakers P.J., Billiet H.A.H., Tussen R. et al. J. Chromatogr. 1978, Vol. 14, pp. 519537. https://doi.org/10.1016/S0021-9673(00)81008-0

16. Deineka V.I. Russ. J. Phys. Chem., 2006, Vol. 80, pp. 429-434. https://doi.org/10.1134/ S0036024406030204

17. Deineka V.I., Kulchenko Ya.Yu., Deineka L.A. et al., Sorbtsionnye i khromatograficheskie protsessy, 2016, Vol. 16, No 4, pp. 464-471.

18. Kulchenko Ya.Yu., Deineka V.I., Chulkov A,N. et al. Sorbtsionnye i khromatograficheskie protsessy, 2018, Vol. 18, No 4, pp. 588-597.

Дейнека Виктор Иванович - Д.Х.н., профессор кафедры общей химии, Белгородский государственный национальный исследовательский уни- University, Belgorod, e-mail deineka@bsu.eduru верситет, Белгород

Саласина Ярослава Юрьевна - ассистент кафедры общей химии, Белгородский государственный национальный исследовательский университет, Белгород

Salasina Yaroslava Yu. - Assistant of the Department of General Chemistry, Belgorod state national research University, Belgorod, e-mail salasina@bsu.edu.ru

Блинова Ирина Петровна - доцент кафедры Blinova Irina P. - Associate Professor of the Deобщей химии, Белгородский государственный partment of General Chemistry, Belgorod state naнациональный исследовательский университет, tional research University, Belgorod, e-mail: bliБелгород nova@bsu.edu.ru

Дейнека Людмила Александровна - к.х.н., до- Deineka Lyudmila A. - Associate Professor of the цент кафедры общей химии, Белгородский госу- Department of General Chemistry, Belgorod state naдарственный национальный исследовательский tional research University, Belgorod, e-mail: университет, Белгород deyneka@bsu.edu.ru

Варушкина Светлана Михайловна - к.б.н., Varushkina Svetlana M. - senior lecturer of the старший преподаватель кафедры общей химии, Department of General Chemistry, Belgorod state naБелгородский государственный национальный ис- tional research University, Belgorod, e-mail: varushследовательский университет, Белгород kina@bsu.edu.ru

Чулков Андрей Николаевич - старший специ- Chulkov Andrey N. - senior specialist, Belgorod алист, Белгородский филиал «Центр оценки каче- branch "Center for quality assessment of grain and ства зерна и продуктов его переработки», Белго- products of its processing", Belgorod, e-mail: род afh87@mail.ru

Селеменев Владимир Федорович - д.х.н., профессор кафедры аналитической химии Воронежского государственного университета, Воронеж
Selemenev Vladimir F. - Professor of the Department of Analytical Chemistry, Voronezh State University, Voronezh 